(C) Copyright 2018: Editum. Servicio de Publicaciones de la Universidad de Murcia. Murcia (Spain) ISSN print edition: 0212-9728. ISSN on line edition (http://revistas.um.es/analesps): 1695-2294. On line edition License Creative Commons 4.0: BY-NC-ND

\title{
How Sense of Agency and Sense of Ownership can Affect Anxiety: A Study Based on Virtual Hand Illusion
}

\author{
Zhang Jing ${ }^{1,2}$, Chen Wei ${ }^{3,4 *}$, and Qian Yanyan ${ }^{5}$ \\ 1 Institute of Psychological Health, Hangahou Dianzi University, Hangahou(China). \\ 2 Leiden Institute for Brain and Cognition, Leiden University, Leiden(Netherlands). \\ 3 Department of Psychology, Shaoxing University, Shaoxing(China). \\ 4 Department of Psychology, The Education University of Hong Kong, Hongkong(China). \\ 5 School of Psychology, Nanjing Normal University, Nanjing(China).
}

\begin{abstract}
Título: Cómo el sentido de la agencia y el sentido de propiedad pueden afectar la ansiedad: un estudio basado en la Virtual Hand Illusion.

Resumen: Usando un programa de ordenador, creamos un entorno virtual para estudiar los posibles impactos del sentido de agencia y sentido de pertenencia sobre la ansiedad. El objetivo del presente estudio es investigar si nuestra configuración podría lograr el efecto similar al que tenía la ilusión de goma tradicional, y cómo el sentido del yo (principalmente sentido de agencia y sentido de pertenencia) afecta la ansiedad de los participantes. Estudio 1, la muestra consistió en 24 estudiantes de primer grado (12 mujeres, 12 hombres) que movieron una mano virtual en $3 \mathrm{D}$ en una situación sincrónica o asincrónica. El estudio 2 incluyó 48 estudiantes de primer o segundo grado (24 mujeres, 24 hombres) que pasaron la escala de calificación SCL-90 y completaron la escala de calificación SCL-90 nuevamente después de realizar una tarea de captura / evitación. En el estudio 1, todos los resultados solo proporcionaron evidencia de una ilusión de mano virtual pero ningún otro efecto. El estudio 2 mostró que las condiciones asincrónicas tenían puntuaciones de ansiedad más altas que las sincrónicas en términos de modalidad y sexo, diferentes imágenes virtuales conducirían a los diferentes sentimientos de ansiedad de los participantes. El sexo en sí mismo no era un factor diferenciador, sin embargo, los hombres y las mujeres reaccionaron de manera diferente en diferentes situaciones. Los resultados indicaron que, en general, el sentido de agencia tiene más impactos en el nivel de ansiedad en comparación con el sentido de pertenencia. Sin embargo, el sentimiento de agencia pareció afectar más a los hombres que a las mujeres, mientras que el sentido de pertenencia ejerció más influencia sobre las mujeres que sobre los hombres. Este hallazgo puede deberse a los diferentes estilos de contribución y habilidades de empatía entre hombres y mujeres.
\end{abstract}

Palabras clave: sentido de la agencia, sentido de pertenencia, ansiedad, estilo de contribución, capacidad de empatía.

\section{Introduction}

The rubber hand illusion (RHI) is the experience of an artificial body part as being one of the real body part (Ehrsson, 2007; Carruthers, 2013; Tsakiris, 2016). This illusion was first reported by Botvinick and Cohen (1998) which was composed of two experiments. In the first experiment, each participant was seated in front of a small table with their left arm resting upon it. The real hand of them was hidden from their view by a standing screen that was positioned between their arm and a life-sized rubber model of a left hand and arm which was placed on the table directly in front of the participant. The participant was asked to sit and fixed their eyes on the artificial hand while experimenters used two small paintbrushes to stroke the rubber hand and the parti-

* Correspondence address [Dirección para correspondencia]:

Chen Wei. Department of Psychology, Shaoxing University, Shaoxing, (P. R. China). E-mail: anti-monist@163.com
Abstract: By using computer program we created a virtual environment to study the possible impacts of sense of agency and sense of ownership on anxiety. The aim of the present study is to investigate whether our setup could achieve the similar effect as traditional rubber hand illusion had, and how sense of self (mainly sense of agency and sense of ownership) affects participants' anxiety. Study 1 the sample consisted of 24 first grade students (12 female, 12 male) who moved a 3D virtual hand in a synchronous or asynchronous situation. Study 2 included 48 first or second grade students (24 female, 24 male) who passed the SCL-90 rating-scale and completed the SCL-90 rating-scale again after they performed a catching/avoiding task. In study 1, all the results only provided evidence for a virtual hand illusion but no other effect. Study 2 showed that asynchronous conditions had higher anxiety scores than synchronous one in terms of modality and sex, different virtual images would lead to participants' different anxious feelings. Sex itself was not a differentiating factor, however, men and women reacted differently in different situations. Results indicated that, in general, sense of agency has more impacts on anxiety level compared with sense of ownership. However, sense of agency seemed to affect male more than female while sense of ownership placed more influence on female than on male. This finding may because the different contribution styles and empathy abilities between men and women.

Keywords: sense of agency, sense of ownership, anxiety, contribution style, empathy ability. cipant's hidden hand as synchronously as possible. After exposing in that environment for ten minutes, all the participants needed to complete a questionnaire in which they had to affirm or deny the occurrence of nine specific perceptual statements. According to the results of the questionnaires, participants seemed to feel the touch not from the hidden brush but from the brush they were viewing, as if the rubber hand had sensed the touch and they felt to own that artificial hand in front of them. This method is widely used with only minor alternations to induce illusions and investigate bodily related themes such as body ownership (Folegatti, Farnè, Salemme, \& de Vignemont, 2012; Germine, Benson, Cohen, \& Hooker, 2013; Jenkinson, Haggard, Ferreira, \& Fotopoulou, 2013; Ocklenburg, Peterburs, Rüther, \& Güntürkün, 2012). Researches based on rubber hand illusion have profound clinical applications in different areas, such as psychiatric disorders (Mussap, McCabe \& Ricciardelli, 2008), limb amputation (Ehrsson et al., 2008), employing neurosurgical techniques (Fontaine, Hamani \& Lozano, 2009). Besides that, 
such studies also benefit some basic researches which concern with human perceptions and emotions. For example, there are researches indicating that events targeting artificial body parts can trigger affective responses (affective resonance) only with perceived body ownership, while neuroscientific findings suggest affective resonance irrespective of ownership (Ma \& Hommel, 2013). Armel and Ramachandran (2003) reported that the illusion goes along with elevated galvanic skin conductance responses (SCR) in the case of possible threat directed at the rubber hand, indicating a kind of "affective resonance" and "emotional involvement" with the artificial hand.

Some researchers adopted the Bayesian perceptual learning to account for the phenomenon of RHI. It was proposed that the RHI is more reliant on synchronicity of stimulation rather than on psychological perceptions such as the visual similarity between the artificial and real hand or the assimilation of the fake hand into one's body image (Ramakonar, Franz \& Lind, 2011). A temporal discrepancy of less than $300 \mathrm{~ms}$ between visual stimulation of the rubber hand and tactile stimulation of the participant's own hand is critical for the multisensory integration process constituting selfbody image to occur (Shimada, Fukuda \& Hiraki, 2009). Further studies have challenged the above simple explanation convincingly, and demonstrated that it is not sufficient to induce the RHI only by synchronous visual and tactile stimulation (Tsakiris \& Haggard, 2005; Zhang, Ma \& Hommel, 2015; Morgan, 2015). Recent studies concerning the factors affect the induction or reduction of RHI suggested that the RH depends not only on synchronous stimulations, but also on the similarity of modality. Which means degree of match between the rubber hand and pre-existing body images (Guterstam, Abdulkaraim \& Ehrsson, 2015; Tsakiris, 2016). For instance, the size and physical form of the hand (hand of apes are more similar to the hand of human than to cat claw). Moreover, Zhang and Chen (2016) adopted distance reference as a new factor to investigate the plasticity of body image, and the result suggests a considerable degree plasticity of body image underlying our body ownership.

However, there is enough evidence to show that this kind of ownership illusion can be obtained by manipulating between the stimulation on artificial hand and real hand respectively. The application of this idea was fully expressed in a virtual hand illusion (VHI). In the experiment of virtual hand illusion, participants sit in front of a screen where visual 3D image of the virtual hand would be presented while having tactile stimulation on their real hidden hand (Padilla et al., 2010). It is indicated that the way of inducing VHI can achieve the same effect as what RHI did. In other words, imposing the same tactile stimulation on both the virtual hand on the screen and the real hand which is hidden from view can let the participants feel the similar experience to that under RHI condition. Sanchez-Vives et al. (2010) showed that by simply manipulating the temporal delay between participants' real movement and the movement of the virtual hand on the screen, a virtual hand illusion can be in- duced even in the absence of tactile stimulation. Slater et al. (2008) found that there were reliable correlations between the impression of hand ownership and hand-related EMG activation, suggesting a connection between perceived ownership and action control.

Compared with RHI, VHI has the following three major advantages. First, for virtual material, in VHI we can have more vivid virtual images of participants' hand while in RHI the shape or size of the fake hand are relatively limited. Secondly, for operation, in VHI it is very easy to guarantee the synchronicity between virtual and real hand while in RHI manual process can't make sure that the brushing on rubber hand is completely synchronizing with that on real hand. Last but not least, for stimulus material, in VHI we can use more novel stimuli such as hit the virtual hand with a ball or a knife while in RHI it seems brushing is the only suitable stimulus.

There are already some studies using this paradigm of VHI to investigate the relationship between sense of ownership and the affective resonance in facing with different kind of emotional events. Yuan and Steed designed an experiment to measured SCR responses to what they considered threats to a virtual hand and found similar elevations as with rubber hands. Participants were asked to play games in virtual environment by operating the hand of an avatar. During the game a virtual lamp would fall on the virtual hand operated by the participants at some point, which induced a reliable increase in SCR. They placed the hand with an arrow as the control condition which produced significantly less increase in SCR. Taken together, they suggested that people emotionally "care" about what they perceive as being a part of their body but not, or not so much, about what they perceive as belonging to the body of someone else (Yuan \& Steed, 2010). However, Ma and Hommel thought that two aspects of Yuan and Steed's study might help explaining this seeming discrepancy. For one, they did not use the standard synchronization technique to induce different degrees of body ownership. For another, the threatening event merely consisted of a virtual lamp falling on the virtual hand. Even though the contact between the lamp and the hand was clearly visible to the participant, it is difficult to judge from the visual display how much pain. Ma and Hommel (2013) adopted the standard synchronization technique to induce the illusion of ownership and replaced the falling of a virtual with a knife. Their findings suggest that ownership was stronger if the virtual hand moved synchronously with the participant's own hand, but his effect was independent from whether the hand was impacted or threatened. In other words, in the face of threat, affective resonance was independent of synchronicity.

\section{Present studies}

However, we think there are still some problems that need to be dealt with. It is necessary to make a distinction between sense of ownership and sense of agency which are two 
major aspects of sense of self closely related but are different from one another. The sense of ownership (SO) is the pre-reflective awareness or implicit sense that one is the owner of an action, movement or thought. The so-called 'ownership' refers to the feeling of 'for-me-ness' or 'mineness', that is, the feeling that an object (such as, a body part or a mental state) is specifically acquainted with one's self. By contract, sense of agency (SA) refers to the subjective awareness that one is initiating, executing, and controlling one's own volitional actions in the world (Jeannerod, 2003). It thus seems to involve both ownership, with respect to an experience of body movement ('my hand moved'), and the reflective experience of voluntary control over that body movement ('I voluntarily made it move') (Haggard, 2017).

Although SA is tightly integrated with SO, they are two different kinds of conceptions. Besides theoretical analysis, statistical extraction of factor analysis also found that SA and SO belong to different factors (Asai, Kanayama, Shu, Koyama \& Kaganoi, 2016). Therefore, what the synchronicity of stimulus induces is sense of agency rather than sense ownership while the shape of virtual image can affect the sense of ownership. The aim of the present study is to investigate 1) whether by manipulating the time between real hand movement and virtual hand movement can induce illusion on Chinese university student, that is if our experiment design can have the equal effect as other VHI experiment did; 2) how sense of self (mainly sense of agency and sense of ownership) affects participants' anxiety.

Several studies (Sanchez-Vives et al., 2010; Ma and Hommel, 2013) have proved that the illusion could be replicated in virtual environment, but our setup is a little bit different from those previous ones, participants manipulated the movements of virtual hand via a mouse instead of their own hands. Therefore, before the actual experiment, we investigated whether we could produce a reliable VHI with our instrument and setup.

\section{Pilot study}

\section{Method}

Participants

The participants were 24 first grade students (12 female, 12 male) from two universities in Hangzhou, China, who were unfamiliar with RHI/VHI and took part in this study voluntarily. The age of the participants ranged between 18 and $21(M=19.98, S D=0.82)$. All the participants were right handed with normal naked or corrected visual acuity. Ethical approval for this study was obtained from the relevant university ethics committee.

\section{Instruments}

The experiment setup was coded by VB.NET. During the whole experiment, participants' hands were covered by a black box $(50 \mathrm{~cm} \times 25 \mathrm{~cm} \times 35 \mathrm{~cm})$. In order to induce more vivid images, the virtual images were presented on a large projection screen $(212 \mathrm{~cm} \times 133 \mathrm{~cm})$. Therefore, the instruments of this study consisted of a computer CPU, a box and a projection screen.

\section{Design and experimental setup}

It was a 2-factor between-subjects design. The two factors were synchronicity (synchronous or asynchronous) and sex (male or female). The purpose of this experiment was to testify were we able to elicit the VHI on both men and women with our program or not.

The study was performed in a virtual environment, which was programmed by VB.NET. A 3D virtual hand was presented on the screen moving either strictly in accordance with the movement of the mouse of slightly delayed $(350 \mathrm{~ms}$ to $500 \mathrm{~ms}$ ). Participants were asked to observe to movement of the virtual hand while moving the mouse with their right hands for 10 minutes. After that, they needed to fill out a 7 item questionnaire which was adopted to evaluate the extent of their VHI experience.

\section{Questionnaire}

Based on the standard 9-item questionnaire (Botvinick \& Cohen, 1998; Ma \& Hommel, 2013; Padilla et al., 2010; Sørensen, 2005; Slater et al., 2008), Ma and Hommel has provided an adapted version to assess the extent to which participants experienced the VHI. We readapted the questionnaire according to our design, and the final statements used in our study were as follows:

Q1. The movements of the image on the screen were caused by myself.

Q2. Sometimes it seemed my own hand was located on the screen.

Q3. The image on the screen began to resemble my own hand, in terms of shape, skin tone, freckles, or some other usual feature.

Q4. Sometimes I felt as if the hand on the screen was my own hand.

Q5. Sometimes I felt as if my real hand was becoming virtual.

Q6. It seemed as if I might have more than one right hand.

Q7. I felt that I can't control the image on the screen.

Question 1, 2, 4, 5 are supposed to indicated the VHI while the other three ones are usually considered fillers.

Q2, Q4 and Q5 are related to the experience of perceiving the hand as one's "own" hand, while Q1 and Q7 are related to the experience of voluntary control and agency. Q3 and Q6 are usually considered as fillers, but given their affective quality, they may also be suspected to be related to the illusion. 


\section{Procedure}

Participants were seated in front of a computer screen, and they could move the mouse with their right hand after the activation of the program. Each participant was either involved in a synchronous situation or an asynchronous one. In the former case, the movement of the virtual hand on the screen was exactly the same as that of the participant. However, in the latter case, virtual hand's movements were delayed from the participant's actual movements by at least $350 \mathrm{~ms}$ to utmost $500 \mathrm{~ms}$. This delayed time was set according to Shimada, Fukuda and Hiraki's study which indicated that a temporal discrepancy of less than $300 \mathrm{~ms}$ between visual and tactile stimulation is crucial for the occurrence of the perceptual illusion (Shimada, Fukuda \& Hiraki, 2009). Participants were asked to manipulate the mouse by moving their hands for 10 minutes, and they were told it was a task which was tend to test the sensitivity of the computer. After the completion of this section, participants were asked to finish a questionnaire with 7 questions by choosing a score in a 7 point (-3 to 3) Likert Scale, ranging from -3 for "strongly disagree" to 3 for "strongly agree".

According to the early VHI studies, if our design is valid, then the VHI could be experienced under the synchronous condition.

\section{Results and Discussion}

We analyzed all the items by means of a 2 (synchronicity) $\times 2$ (sex) ANOVA. Means and standard deviation for all the statements are listed in Table 1.

Table1. Means and Standard Deviation (in brackets) of all the Statements.

\begin{tabular}{|c|c|c|c|c|c|c|c|}
\hline & Q1 & Q2 & Q3 & Q4 & Q5 & Q6 & Q7 \\
\hline Synchronous & $2.25(0.086)$ & $1.50(1.314)$ & $0.33(1.435)$ & $1.08(1.379)$ & $0.00(1.706)$ & $-1.08(1.443)$ & $2.08(0.515)$ \\
\hline Asynchronous & $0.42(1.564)$ & $-1.58(1.311)$ & $-1.42(1.240)$ & $-1.58(1.311)$ & $-2.00(1.206)$ & $-2.25(0.754)$ & $0.67(1.557)$ \\
\hline Male & $1.50(1.243)$ & $-0.25(2.006)$ & $-0.33(1.670)$ & $-0.08(2.065)$ & $-0.67(1.826)$ & $-1.58(1.165)$ & $1.08(1.165)$ \\
\hline Female & $1.17(1.850)$ & $0.17(2.125)$ & $-0.75(1.545)$ & $-0.42(1.782)$ & $-1.33(1.723)$ & $-1.75(1.422)$ & $1.67(1.497)$ \\
\hline$p$ (synchronicity) & 0.001 & $<0.001$ & 0.006 & $<0.001$ & 0.004 & 0.026 & 0.008 \\
\hline$p(\operatorname{sex})$ & 0.485 & 0.448 & 0.469 & 0.565 & 0.288 & 0.735 & 0.237 \\
\hline$p$ (interaction) & 0.022 & 0.292 & 0.662 & 0.773 & 0.591 & 0.501 & 0.864 \\
\hline
\end{tabular}

Note. ${ }^{*} p<.050,{ }^{* *} p<.010,{ }^{* * *} p<.0010$.

A significant main effect of synchronicity on the sum scores of question $1,2,4$, and 5 was found, which indicated the appearance of VHI when there was no time delay existed between the participant's movement and that of the virtual hand, $F(1,23)=60.945, p<.001,\left(\eta_{p}^{2}=.84\right.$. There was no significant difference between the answers of male and female student, $F(1,23)=0.558, p=.464,\left(\eta_{p}{ }^{2}=.04\right.$. That is, all the results provided evidence for a VHI but no other effects.

The outcome clearly showed that our program was able to generate the VHI on both men and women as long as the movement of the virtual hand and participant's real hand was synchronous. In other words, by our design, we can create the situation that one's sense of agency was present or absent.

\section{Formal-Experiment}

\section{Method}

\section{Participants}

Because participants' anxiety level would be taken as a dependent variable, it was important to do homogeneity test in their anxiety level before inviting them to do the experiment. All the candidates were asked to finish the SCL-90 rating scale before the experiment, and only those normal students with similar anxiety scores were finally chosen to take part in the experiment (According to the norm of SCL-90 in China, anyone who got total score higher than 160 , or the number of positive items more than 43, or any factor higher than 2 should be considered to do positive screening. All the students we chose had not showed any above-mentioned positive signs). The final participants were 48 first or second grade students (24 female, 24 male) from two universities in Hangzhou and Shaoxing respectively, China, who were unfamiliar with RHI/VHI and took part in this study voluntarily. The age of the participants ranged between 18 and 22 $(M=20.67, S D=1.05)$. All the participants were right handed with normal naked or corrected visual acuity. Ethical approval for this study was obtained from the relevant university ethics committee.

\section{Instruments}

The instruments in the experiment were the same as in pilot study.

\section{Design and Procedure}

It was a 3-factor between-subjects design. The three factors were synchronicity (synchronous or asynchronous), modality (human hand or cat's claw) (see Figure 1B, 1C) and sex (male or female). The purpose of this experiment was to investigate whether sense of agency and sense of ownership could affect anxiety during an emotional event.

Participants were asked to observe the movement of the virtual human hand/cat claw while moving the mouse with their right hands (see Figure 1A). 

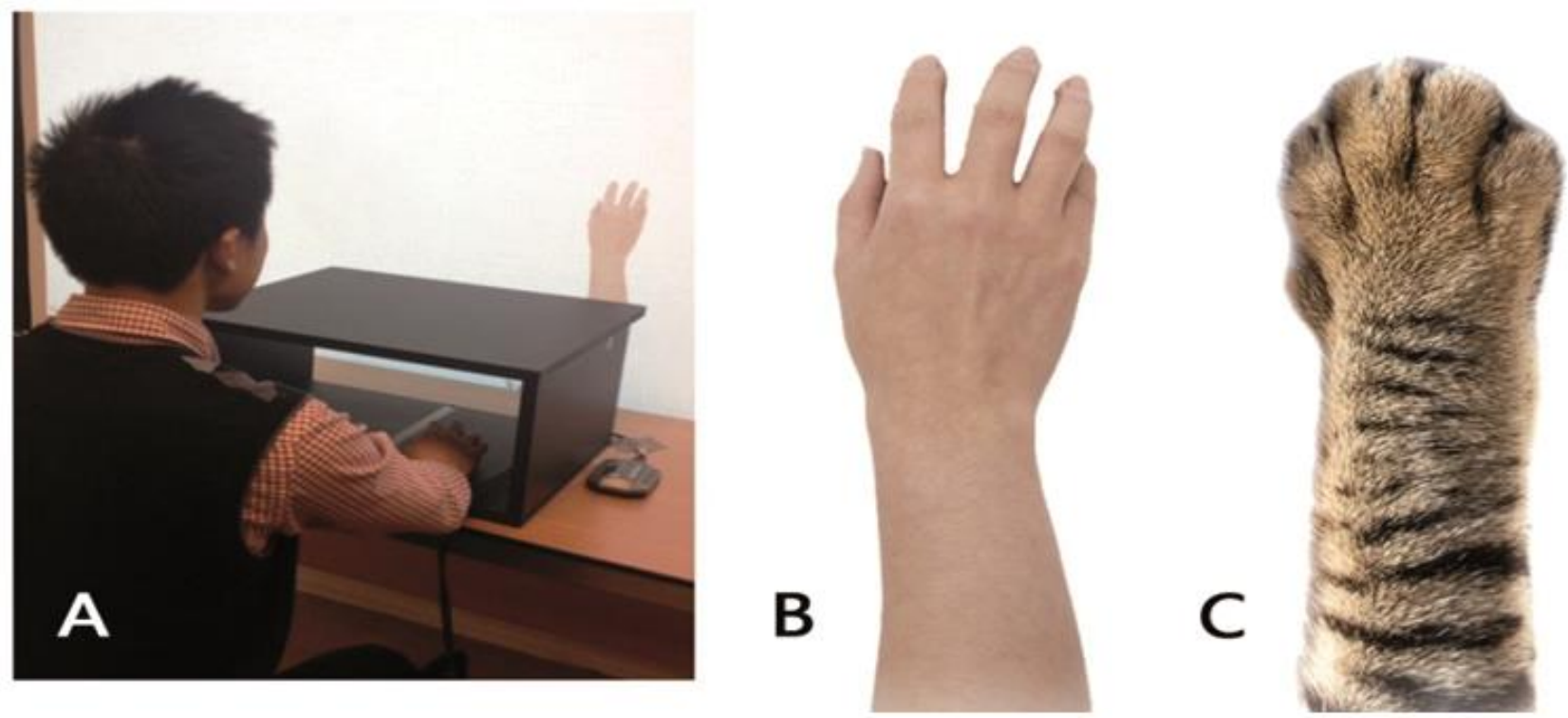

Figure 1. Equipment and Virtual Images.

Synchronicity and Modality were two between-group factors. That is, the movement of the virtual "hand" would be either synchronous or asynchronous with the movement of the mouse which was controlled by participant's actual hand. Besides, the virtual "hand" would be either seen the same as a human hand or a cat's claw. Therefore, four situations can be obtained as follows. According to our theory hypothesis, these four situations would generate four different status of sense of agency (SA) and sense of ownership (SO) which would finally affect participant's behaviors and emotions (see Table 2). The order of the two synchronicity conditions as well as the order of the modality of virtual "hand" was balanced across participants.

Table 2. Different Status of Sense of Self

\begin{tabular}{|c|c|c|}
\hline & Synchronous & Asynchronous \\
\hline Human hand & $\mathrm{SA} \sqrt{\mathrm{SO}} \sqrt{ }$ & $\mathrm{SA} \times \mathrm{SO} \sqrt{ }$ \\
\hline Cat's claw & $\mathrm{SA} \sqrt{ } \mathrm{SO} \times$ & $\mathrm{SA} \times \mathrm{SO} \times$ \\
\hline
\end{tabular}

The procedure was very similar to that in the pilot experiment, the movement between the virtual image and participant's real hand was either synchronous or asynchronous, except for participants needed to perform a catching/avoiding task while moving the mouse and watching the movements of the virtual image on the screen. Participants saw a virtual coin or knife coming down from the top of the screen, and what they needed to do was to catch as many coins as they can while avoiding the cut of the falling knife. There were scores of their performance during the game displayed on the top right corner of the screen. Catching a coin or avoiding a knife would add a point while losing a coin or cutting by a knife would lose a point. There were four situations in this experiment. Each participant encountered one. They were asked to play this cat- ching/avoiding game for 10 minutes. At the end of the game, there would be a message printed on the screen which told them the results of their performances. After the game, participants were asked to complete a Self-Rating Anxiety Scale (SAS, see Appendix) which contains 20 statements related to anxiety. Participants were asked to rate the statements from 1 (a little of the time) to 4 (most of the time) according to their current or recent emotional state. Some of these items associate higher anxiety with higher scores while the others associate higher anxiety with lower scores (5, 9, $13,17,19)$.

It seems that using different scales to assess anxiety was not a wise decision, but for the following considerations, we chose SAS finally as the anxiety measurement of our experiment.

1. The assessment of SCL-90 was just a way to screen participants, their anxiety would not be used as a baseline.

2. SAS has only 20 items, it would be much easier and quicker to finish, as the anxiety level raised by the experiment might decrease in no time.

3. In order to compare, we asked all the participants to come back to our lab anddo the SAS one more time the next day after the experiment, in which the mean score of all the participants was 34.130 with standard deviation 6.617 .

\section{Results}

We analyzed the anxiety scores by means of a 2 (synchronicity) $\times 2$ (modality) $\times 2$ (sex) ANOVA. See Figure 1 for mean anxiety scores according to synchronicity, modality and sex. Means and standard deviation for all independent variable levels are listed in Table 3. 
Table 3. Means and Standard Deviation for all independent variables

\begin{tabular}{lcccccc}
\hline & Synchronous & Asynchronous & Male & Female & HumanHand & CatClaw \\
\hline Mean & 33.42 & 41.50 & 38.79 & 36.13 & 39.75 & 35.17 \\
SD & 4.889 & 5.861 & 8.049 & 4.884 & 7.317 \\
\hline
\end{tabular}

Significant differences were found $(F(1,47)=36.826, p$ $<.001,\left(\eta_{p}^{2}=.60\right)$ in all dimensions of modality and sex. In terms of modality and sex, participants had higher average anxiety scores under asynchronous conditions than those under synchronous conditions did. A significant main effect of modality $\left(F(1,47)=11.840, p=0.001,\left(\eta_{p}^{2}=.34\right)\right.$ showed that different virtual images would lead to participants' different anxious feelings. There was no main effect of sex. However, the highest mean anxiety score $(M=44.67)$ was obtained by male participants under asynchronous conditions while viewing the human hand virtual image, and the lowest $(M=29.33)$ was obtained by female participants under synchronous conditions when the virtual image was cat claw. That means, when involving in different situations, men and women reacted differently (See Figure 2).

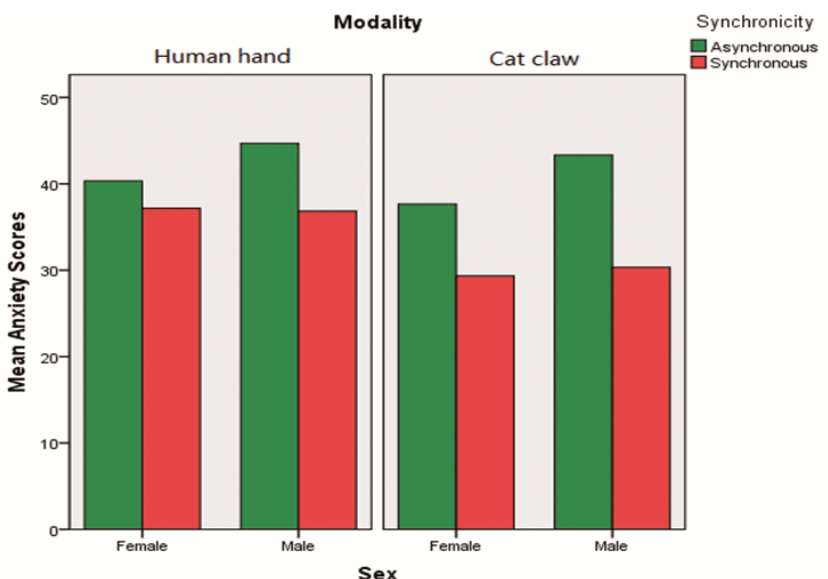

Figure 2. Mean Anxiety Scores According to Synchronicity, Modality and Sex.

\section{Discussion}

In the present study we investigated how the status of our sense of self can have impact on anxious feelings. We performed two experiments to do the research. The pilot experiment was aim to demonstrate that our design can elicit the VHI which has intimate connection with the sense of self. The second experiment was designed to reveal the relationship between sense of self and anxiety, which chose anxiety scores as the dependent variable while synchronicity, modality and sex as three independent variables. Our findings suggest two conclusions:

First, the results of this study showed that in general, asynchronous conditions had higher anxiety scores than synchronous one, no matter for male or female, and has nothing to do with the modality of virtual image, which indicated that the absence of sense of agency may lead to higher anxiety levels. According to our hypothesis, synchronicity will affect the sense of agency the lack of which may lead to the decrease of sense of control (Gallagher, 2012). This factor reflects the sense of controllability of a target, including our own body, and the intentionality of our own action (Asai, Kanayama, Shu, Koyama \& Kaganoi, 2016). That is, people are tend to be more anxious when facing uncontrolled situations. Besides, synchronicity had more impacts on people's anxiety level than modality did. In other words, sense of agency played more important role in emotional mediation than sense of ownership did, even the latter was also crucial to anxiety level according to our study. However, sense of agency seemed to affect male more than female while sense of ownership placed more influence on female than on male. To be specific, men showed more differences between synchronous and asynchronous conditions than women did, and women showed more differences between human hand and cat claw conditions than men did. This finding may because the different contribution styles and empathy abilities between men and women.

Second, viewing a human hand was easier to arouse participants' anxious feelings than facing a cat claw. According to our hypothesis, that was due to the affection of sense of ownership on emotional feelings. Even for a virtual image, a body part that was similar with our own body could make us have more empathy than others, such as a cat claw. That is why we are more likely to have sympathy for our friend generation. Under most circumstances, men's anxiety scores were higher than women's except for synchronous and human hand conditions in which men's anxiety scores were slightly lower than women's, which was very odd. As far as we can tell, women are more sensible than men, so they should felt more anxious than men. However, in our present study, the anxiety scores were affected by people's sense of agency and sense of ownership, which determined that participants' attribution styles were also crucial. Because women are more likely to do external attribution while men prefer internal attribution (Wang, Chiang, Tsai, Lin, \& Cheng, 2013; Rim, 1990), when dealing with the emotional feelings aroused by the catching $\&$ avoiding task, the attribution style of female helped them to ease.

Taken together, our finding suggest that the degree of anxiety revealed by SAS can be predicated by the degree and type of participants' illusion, which indicates such a possibility that emotion is probably the key component for binding minimal self and narrative self. However, it is regrettable that in this study we did not measure other categories of emotion, such as fear, anger, et al. Further studies on the one hand can try to adopt more measurements, on the other hand need to investigate the boundaries between minimal self and narrative self.

Nevertheless, there are some theoretical and practical 
meanings of this study. In clinical application, applying synchronous touches to the stump has been used to help limb amputees to experience a rubber hand as part of their own body. Such studies outline a simple method for transferring tactile sensations from the stump to a prosthetic limb, and the final goal is to develop artificial limbs that feel like like a real parts of the body (Ehrsson., et al, 2008). According to previous studies, the key factor of such attempt is the visual-tactile synchronous stimulation, but our findings suggest we may need to consider more. For female patients,

\section{References}

Armel, K. C., \& Ramachandran, V. S. (2003). Projecting sensations to external objects: Evidence from skin conductance response. Proceedings of the Royal Society B: Biological Sciences, 270(1523), 1499-1506.

Asai, T., Kanayama, N., Shu, I., Koyama, S., \& Kaganoi, S. (2016). Development of embodied sense of self scale (ESSS): Exploring everyday experiences induced by anomalous self-representation. Frontiers in Psychology, 7, 1005.

Botvinick, M., \& Cohen, J. (1998). Rubber hands 'feel' touch that eyes see. Nature, 391(6669), 756.

Carruthers, G. (2013). Toward a cognitive model of the sense of embodiment in a (rubber) hand. Journal of Consciousness Studies, 20, 33-60.

Ehrsson, H.H. (2007). The experimental induction of out-of-body experiences. Science, 317, 1048.

Ehrsson, H. H., Rosen, B., Stockselius, A., Ragno, C., Kohler, P., \& Lundborg, G. (2008). Upper limb amputees can be induced to experience a rubber hand as their own. Brain, 131, 3443-3452.

Folegatti, A., Farnè, A., Salemme, R., \& de Vignemont, F. (2012). The rubber hand illusion: Two's a company, but three's a crowd. Consciousness and Cognition, 21(2), 799-812.

Fontaine, D., Hamani, C., \& Lozano, A. (2009). Efficacy and safety of motor cortex stimulation for chronic neuropathic pain: Critical review of the literature. Journal of Neurosurgery, 110(2), 251-256.

Gallagher, S. (2012). Multiple aspects in the sense of agency. New Ideas in Psychology, 30(1), 15-31.

Germine, L., Benson, T. L., Cohen, F., \& Hooker, C. I. L. (2013). Psychosisproneness and the rubber hand illusion of body ownership. Psychiatry Research, 207(1-2), 45-52.

Guterstam, A. Abdulkaraim, Z., \& Ehrsson, H. H. (2015) Illusory ownership of an invisible body reduces autonomic and subjective social anxiety responses. Scientific Reports, 5, 9831.

Haggard, P. (2017). Sense of agencyin the human brain. Nature Reviews Neuroscience, 18(4), 196-207.

Jeannerod, M. (2003). The mechanism of self-recognition in humans. Bebavioural Brain Research, 142(1-2), 1-15.

Jenkinson, P. M., Haggard, P., Ferreira, N. C., \& Fotopoulou, A. (2013). Body ownership and attention in the mirror: Insights from somatoparaphrenia and the rubber hand illusion. Neuropsychologia, 51(8), 14531462.

Ma, K., \& Hommel, B. (2013). The virtual-hand illusion: Effects of impact and threat on perceived ownership and affective resonance. Frontiers in Psychology, 4, 604.

Morgan, H. L. (2015). Sense of agency and sense of ownership: Arguing against a dissociation and fora critical role for multisensory binding. Psychology of Consciousness: Theory, Research, and Practice, 2(3), 222-236. sense of ownership may be more crucial than sense of agency for them, while for male patients, sense of agency may play a more role than sense of agency.

Acknowledgments.- This work was supported by Project of the Humanities and Social Science Research of the Ministry of Education of China (17YJCZH243), The National Social Science Foundation (16CZX015), General Scientific Research Project of Zhejiang Education Department (Y201636521).

Mussap, A. J., McCabe, M. P., \& Ricciardelli, L. A. (2008). Implications of accuracy, sensitivity, and variability of body size estimations to disordered eating. Body Image, 5(1), 80-90.

Ocklenburg, S., Peterburs, J., Rüther, N., \& Güntürkün, O. (2012). The rubber hand illusion modulates pseudoneglect. Neuroscience Letters, 523(2), 158-161.

Padilla, M. A., Pabon, S., Frisoli, A., Sotgiu, E., Loconsole, C., \& Bergamasco, M. (2010). Hand and arm ownership illusion through virtual reality physical interaction and vibrotactile stimulations. In A. Kappers, J. Van Erp, W. Tiest \& F. Van Der Helm (Eds.), Lecture Notes in Computer Science (Vol. 6192, pp. 194-199). Berlin: Springer-Verlag Berlin.

Ramakonar, H., Franz, E. A., \& Lind, C. R. P. (2011). The rubber hand illusion and its application to clinical neuroscience. Journal of Clinical Neuroscience, 18(12), 1596-1601.

Sørensen, J. В. Ø. (2005). The alien-hand experiment. Phenomenology and the Cognitive Sciences, 4(1), 73-90.

Rim, Y. (1990). Styles of attribution and of coping. Personality and Individual Differences, $11(9)$, 973-976.

Sanchez-Vives, M. V., Spanlang, B., Frisoli, A., Bergamasco, M., \& Slater, M. (2010). Virtual hand illusion induced by visuomotor correlations. PLoS One, 5(4), e10381.

Shimada, S., Fukuda, K., \& Hiraki, K. (2009). Rubber hand illusion under delayed visual feedback. PLoS One, 4(7), e6185.

Slater, M., Perez-Marcos, D., Ehrsson, H. H., \& Sanchez-Vives, M. V. (2008). Towards a digital body: The virtual arm illusion. Frontiers in $\mathrm{Hu}$ man Neuroscience, 2, 6.

Tsakiris, M., \& Haggard, P. (2005). The rubber hand illusion revisited: Visuotactile integration and self-attribution. Journal of Experimental Psychology: Human Perception and Performance, 31(1), 80-91.

Tsakiris, M. (2016). The multisensory basis of the self: From body to identity to others. The Quarterly Journal of Experimental Psychology, 1-28. DOI 10.1080/17470218.2016.1181768

Wang, A., Chiang, J. T., Tsai, C., Lin, T., \& Cheng, B. (2013). Gender makes the difference: The moderating role of leader gender on the relationship between leadership styles and subordinate performance. Organizational Behavior and Human Decision Processes, 122(2), 101-113.

Yuan, Y., \& Steed, A. (2010). Is the rubber hand illusion induced by immersive virtual reality? IEEE Virtual Reality, 95-102.

Zhang, J., \& Chen, W. (2016). Is body image plastic? The impact of synchrony and distance reference frame on body ownership. Acta Psychologica Sinica 48(8), 933-945.

Zhang, J., Ma, K., \& Hommel, B. (2015). The virtual hand illusion is moderated by context-induced spatial reference frames. Frontiers in Psychology, 6,1659.

(Article received: 26-08-2017; revised: 04-12-2017; accepted: 05-02-2018) 


\section{Appendix: Zung Self-Rating Anxiety Scale (SAS)}

For each item below, please place a check mark $(\checkmark)$ in the column which best describes how often you felt or behaved this way during the past several days.

\begin{tabular}{|c|c|c|}
\hline Place check mark $(\checkmark)$ in correct column & $\begin{array}{l}\text { A Little } \\
\text { of the time }\end{array}$ & $\begin{array}{c}\text { Some } \\
\text { of the time }\end{array}$ \\
\hline
\end{tabular}

1. I feel more nervous and anxious than usual.

2. I feel afraid for no reason at all.

3. I get upset easily or feel panicky.

4.I feel like I'm falling apart and going to pieces.

5. I feel that everything is all right and nothing but will happen.

6. My arms and legs shake and tremble.

7. I am bothered by headaches neck and back again.

8. I feel weak and get tired easily.

9. I feel calm and can sit still easily.

10. I can feel my heart beating fast.

11. I am bothered by dizzy spells.

12. I have fainting spells or feel like it.

13. I can breathe in and out easily.

14. I get feelings of numbness and tingling in my fingers \& toes.

15. I am bothered by stomach aches or indigestion.

16. I have to empty my bladder often.

17. My hands are usually dry and warm.

18. My face gets hot and blushes.

19. I fall asleep easily and get a good night's rest.

20. I have nightmares.

Source: William W. K. Zung. A rating instrument for anxiety disorders. Psychosomatics. 1971 